\title{
The Drawn Landscape in 3D Databases: The Management of Complexity and Representation in the Historical City
}

\author{
By Sandro Parrinello* \\ Francesca Picchio ${ }^{\dagger}$ \\ Pietro Becherinit \\ Raffaella De Marco $^{+}$
}

The complex structure of landscape has motivated recent research into representative systems capable of expressing the complex relationships present within an urban place. Updating the ways of its reading, research has attempted to identify more or less complex urban scenarios, profoundly different from each other both from a formal, cultural and perceptive point of view. The contribution presents examples of methods of analysis, digital acquisition and processing of documentation systems of these landscapes, in order to analyse not only formal differences, but also to structure a documentation and representation methodology for problems of management and planning of the city and territory. The virtual space configures itself through a systematic and structured drawing, demonstrating how interactive reality-based digital models can constitute valid systems of representation of the real landscape. The virtual space maintains relationships and exchanges data with its user, simulating reality and becoming a place where project and experimentation are set in a simplified form to explain critical readings useful for identifying key values that will guide the project. $3 D$ models, together with databases, configure landscapes that outline the future of research through the study of systems of interaction between man, drawing and virtual space. In particular, the contribution deals with the three-dimensional representation of the historical center of the city of Pavia and the territorial relationship with its province, analysing documentation systems that, through digital drawing, contribute to the enhancement and awareness of values of urban landscape heritage. 3D models, used as planning tools, become elements of cohesion between space and time, bringing to light the Roman and Longobard city, till its current configuration, laying the foundations for the project of the city of the future. Each formal choice will be oriented on values of conservation, restoration and interpretation of the historical and cultural dimension of the city.

\footnotetext{
*Associate Professor, University of Pavia, Italy.

${ }^{\dagger}$ Research Fellow, University of Pavia, Italy.

${ }^{\star}$ PhD Student, University of Pavia, Italy.

${ }^{+} \mathrm{PhD}$ Student, University of Pavia, Italy.
} 


\section{Introduction $^{1}$}

"The amount of information in architecture is increasing dramatically while the level of the description techniques is significantly lower than the iconicity of the original form. This is the reason why returning architectures in $3 D$ format not only helps to visualize or more intuitively store information about them, but it is also useful for defining them and making them clearer in order to draw them."

(Abraham Moles)

With the increase of digital archives and digital network services, the virtual information space increases and sets new horizons for information and communication systems for urban space management. ${ }^{2}$ Parallel to the growing demand for data management systems, also allocated to real objects ("Internet of Things,") there is the lack of a digital database of historic centers that protects national heritage by facilitating planning and development of the territory. In particular, most of the transformations of urban fabrics and territory still take place without a strict control that allows to assess its congruity in relation to the landscape system in which they insist and, in parallel, the inability to set up different models of analysis involves a limitation in the management and planning of potentials of the city that instead requires precise answers to different levels of analysis. A historical center taken in its entirety represents a container of a myriad of information, and the attempt to study and document its characteristics requires an archive that can be easily consulted and implemented. For this reason, the need to produce a system of remote use based on databases, whose images replicate those of the real city, amplify the expressive potential of urban drawing, defining a management system able to simulate the activities of reality giving place to a real new survival opportunity (second life) of cultural heritage. ${ }^{3}$ The survey process from which the 3D database will be generated will guarantee the metric and formal reliability of the virtual space, where vector elements will approximate real phenomena and where information will be allocated to these specific graphic elements, with the further possibility to parameterize as far as possible the dimensional values of different environments or, as already developed for some experiences of virtual reality for Cultural Heritage, the parameter of time. The virtual city (Figure 1) thus becomes a discrete model of real space, critically interpreted and redrawn according to an alternation of automatic procedures and drawings from which to bring out a simplified form of the main features of the complex space.

1. The author of this paragraph is Sandro Parrinello.

2. S. Parrinello, "Rilevare, disegnare e organizzare la città digitale," in Proceeding UID 2015 Disegno e città (ed.) A. Marotta and G. Novello (Torino: Gangemi Editore, 2015).

3. M. G. Cianci, Dalla linea ideale alla città virtuale (Firenze: Alinea, 2008). 

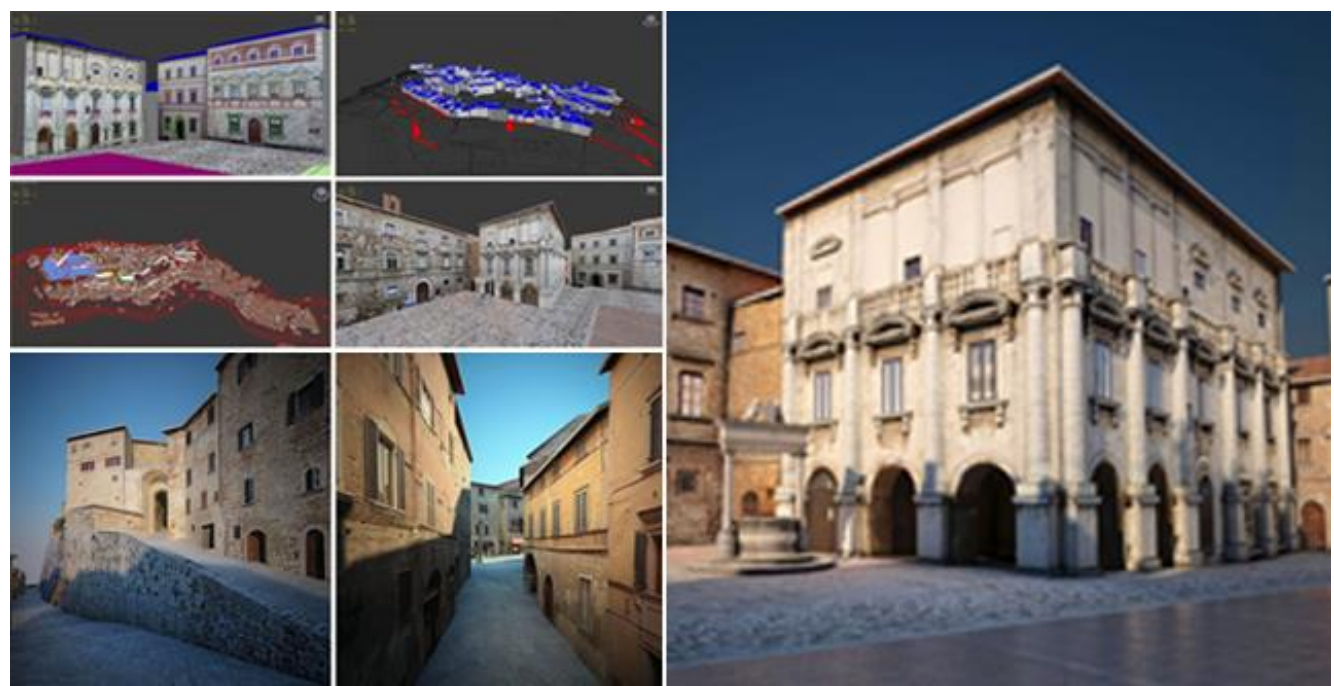

Figure 1. Images of 3D Model of the Historical Center of Montepulciano, Modelled and Mapped in 3D Studio Max, Inserted on a Web Platform for Navigation and Use in Real-time. 3D Models of Buildings Overlooking the Main Square of the Historic Center have been enriched with More Complex Threedimensional Details while, for an Easier Management of the General Model of the City, the Other Buildings are made with a Minimum Number of Polygons.

This model can be generated through numerous methodologies, which aim to optimize surfaces and volumes by identifying a correspondence between the logical decomposition of the urban model and the creation of three-dimensional graphic elements necessary for the allocation of data. Moreover, it is necessary that data are appropriately ordered, to ensure that the guidance system within the model guarantees a general good functioning of the system, and that the database can produce meaningful synthesis. Database and model are configured in this way through layers, different levels of information that show the drawing of the city itself, stratified by the events that have led to its growth and characterized its image, as presented at the time of the survey. To ensure that the database does not age at the time of its creation, its maintenance over time becomes fundamental, and "time" itself becomes a fundamental parameter capable of making the urban form dynamic and variable; it will be possible to travel in the past, through the processes of genesis of the city, but also to plan or configure the future, giving to the structure of the digital archive the way to modify itself with the change of the real parameters that define the image and the status of places. ${ }^{4}$

4. D. Marini, M. Bertolo and A. Rizzi, Comunicazione visiva digitale: fondamenti di Eidomatica (Milano: Addison Wesley, 2001). 


\section{Cultural Context and Research Theme ${ }^{5}$}

The issue of documentation of historical centers and urban landscapes has always represented, and today even more clearly, a line of research of primary importance for the Italian national territory. Its strength lies in the collective intention to prepare a study of systems of analysis and interpretation of the phenomena that exist in the definition of components characterizing both the architectural and urban scale, which is not limited to the image of the city but also highlights the need of policies for safeguarding and protecting heritage. The urban reality in Italy has been at the center, since the '60s, of episodes of spreed and expansion typical of post-war reconstruction phenomena, which have generated a renewed confidence in architectural practice as a physical instrument of human living. The diffusion of reconstruction plans, housing systems and infrastructural installations has configured a new generation of architects and architectures, within new ideals of modernity both in formal and material contents of buildings and new technologies. In this way, constructive interventions were concentrated mainly in the field of new buildings, devoting for existing buildings intervention policies poor of sensitivity towards the previous architectural impressions of historical urban centers. The attention to the historical patrimony of inhabited centers and its protection has regained strength in Italian scene since the $80 \mathrm{~s}$, in particular following great telluric events (starting from that of Messina, in Sicily, in 1975) that highlighted the "fragile" nature of historic villages and their level of insecurity in the absence of appropriate technical actions. The theme of preservation of historical architecture, as an expression of secular values and physical image of constructive and stylistic parameters, has thus begun to express itself starting from the most ancient cities (such as Florence, Rome, Turin...,) with theoretical foundations of the first regulatory provisions for documentation and planning on the existing built heritage, till to extend its conservative policy to secondary centers, more rural but also characterized by prestigious historical values. Recent episodes of earthquakes and natural disasters occurred in Italy (in particular the events of L'Aquila in 2009, of Amatrice, Accumuli and Norcia in 2016 and of Montereale in 2017) have generated a renewed awareness of public opinion and administrations towards the value of peripheral historical centers and the persistent absence of adequate documentation systems that allow restoration or reconstruction interventions, in particular in case of collapse of entire portions of the city. The architectural richness linked to traditional building and typological systems, due to the numerous cultural trends and events that have affected the Italian territory in the course of history, past and recent, expresses its multiple values in a large collection of morphological characters and style, developing a national heritage with a high complexity of classification, control and protection. Buildings of historic Italian centers, traditionally, were born and remained linked to the original Roman structure, maintained even in medieval times, and then were affected by specific local formal directions of planning and renewal interventions, that have led to profound changes in the image of cities in the last two centuries.

5. The author of this paragraph is Francesca Picchio. 
The demolition of perimetrical military walls and medieval towers, the reconfiguration of main road systems, the construction of nineteenth-century palaces, the conformation of urban centers diffused from small to large scale and their relationship with the surrounding landscape thus become actions "of" and "on" the city that contribute to define a real framework in which the contemporary operator is both "receptor" of information and suggestions coming from the built landscape ${ }^{6}$ and "emitter" of new impulses and actions on the city. This system of relationships finds new expression and interaction in the tools of the "digital age," in a virtual environment of connection between users and information where architectural heritage actively interacts with its digitized image, transformed into a n-dimensional byte system of storage where each dimension is an expression of the implicit informative content, catalogued in levels of historical, morphological, constructive and materic analysis of buildings ${ }^{7}$. The lines of documentation applied attempt to follow the provisions of Digital Agenda 2020 of European Committee, ${ }^{8}$ with initiatives of Digitation of Cultural Heritage, online accessibility and digital preservation that promote possibilities of eGovernance where man and drawing interact as animated subjects in a simulated but reliable space, where every decision of planning, intervention, restoration and conservation finds its virtual experimentation for the following implementation in the physical reality. ${ }^{9}$ These possibilities coexist and expand through the innovations allowed by the continuous developments in the management of Big Data coming from the digitization of the built heritage: 3D databases on architectural systems, through their completeness and reliability developed by preliminary analysis and survey operations, affirm themselves as a gold standard within documentary implementation protocols, and identify a field of application and experimentation that, between methodological acquisition research and planning purposes, develops the representative tradition towards new frontiers of evolution and interaction between man, architecture and landscape. ${ }^{10}$

6. R. Assunto, "Metaspazialità del Paesaggio," in Il paesaggio e l'estetica (ed.) Rosario Assunto (Palermo: Edizioni Novecento, 1994).

7. S. Brusaporci, Sistemi informativi integrati per la tutela, la conservazione e la valorizzazione del patrimonio architettonico e urbano (Roma: Gangemi, 2010).

8. European Commission Directorate-General for Communication, The EU explained: Digital Agenda for Europe (Luxemburg: Publications Office of the European Union, 2014).

9. A. Clementi, Interpretazioni di paesaggio. Convenzione europea e innovazioni di metodo (Roma: Meltemi, 2002).

10. S. Bertocci and M. Bini, Manuale di rilevamento architettonico ed urbano (Novara: CittàStudi, 2012). 


\section{Integrated Survey Methodologies as Documentation Systems for the Development of Reliable 3D Models on Urban Areas ${ }^{11}$}

Research in the field of documentation of Italian urban centers has seen in recent decades an exponential growth in the use of digital technologies for the acquisition and post production of data on built fabrics. ${ }^{12}$ The traditional surveying phases, aimed at realizing drawings intended to describe the urban space, its architectural aspects and the characteristics of the individual buildings, have been transformed into a more general objective of defining a corresponding "digital urban image," through which to acquire and control the overall morphology of elements of a given settlement context or historical landscape. The research, applied in some Italian historical centers, allowed operators to be able to rely on different methodological protocols, each one aimed at results, and consequently output elaborates, profoundly different from each other but developed with complementary and integrable languages and systems. Urban space drawings are thus effective both to communicate a high diversity of contents in unified 3D models, viewable on interactive platforms, and to express in a more technical way graphic conventions, geometric and proportional characteristics and construction peculiarities of each building unit. Each sector concerned, from the field of cultural heritage ${ }^{13}$ to that of architectural survey, has developed a different system of structuring data, and of managing not only the image but all the different components in which the urban information content has been deconstructed and reorganized to compose descriptive elements. In this way, each single field of survey has generated its own response to digital applications and developed analysis methodologies based on specific but different theoretical models. The experience of digital survey has developed processes of integration of technological tools for the achievement of digital data, which can be exploited in the form of virtual space, ensuring metric accuracy and material correspondence, primary objectives of documentary operations, through indirect acquisition technique of reality, defined reality-based and classified in: techniques based on active sensors (range-based,) which employ instruments capable of emitting an infrared signal reflected from the surfaces and recorded by the instrument in order to obtain its spatial coordinates (range) in the form of points cloud; techniques based on passive sensors (image-based,) which exploit the colorimetric properties of the environment to acquire images, process them and derive $3 \mathrm{D}$ information from them. Range-based instruments applied to the survey of historical fabrics are laser scanners (terrestrial or mobile) and total stations (for the punctual restitution of coordinates and positions in space, associated to specific morphological points of the urban system.) In particular, in the architectural and cultural heritage field, laser scanners (triangulation type or "time of flight" type) have found great success and have greatly facilitated the method within metric

11. The author of this paragraph is Pietro Becherini.

12. D. Coppo and C. Boldo, Rilievo urbano. Conoscenza e rappresentazione della città consolidata (Firenze: Alinea, 2010).

13. V. Baldacci, Il Sistema dei Beni Culturali in Italia. Valorizzazione, progettazione e comunicazione culturale (Firenze: Giunti Editore, 2004). 
and formal data can be acquired relating to simple architectural buildings or large building comparts; as active sensors, these tools have been able to supply large amounts of 3D data directly and quickly, returning them in the form of point clouds, dense but still unstructured. Among image-based systems, the photomodelling $^{14}$ from photographic acquisition has seen a growing use in architectural and urban surveys, offering opportunities for documentary restitution of wall surfaces and morphological systems with optimization of colorimetric scales of materials and an adequate reliability of results for 3D geometric restitution. The main advantage of passive systems and related image processing techniques, compared to the use of laser scanner tools, is represented by the convenience and transportability of sensors, as well as the greater simplicity of acquisition of photographic images in urban analysis sites. Images can be acquired from aerial views through cameras on telescopic shafts, drones (more generically UAV) or digital terrestrial cameras (reflex.) Recently drones, similarly to the use of telescopic shafts, have had a great success and development both in urban and architectural field, allowing to acquire horizontal or oblique images from elevated shooting stations with low costs and discrete acquisition reliability. Their diffusion inserts in the documentary practices, respect to the use of terrestrial cameras, new perspectives of analysis where the increase of the vertical visual level introduces an amplified system of observation and representation, in particular for the analysis of systems of urban buildings, no longer limited to human proportions but dimensionable on the basis of specific requests of each built environment. The instrumental evolution highlights, in all its applications, their impossibility of independence from the constant supervision of the survey operator, but on the contrary underlines its integration with high data acquisition capacity to guarantee a broader and complete knowledge of the fabrics history and their stratification. The eye of the camera captures the materic reality by observing it dynamically and from above, and for this reason developing a system of comprehension and global and complete knowledge. If image-based instruments based on their affordability of costs, availability and speed of acquisition are classified as fast survey methodological systems for excellence, on the other the need for precision at high levels of metric reliability still remains associated with the integration of range-based instrumentation as reference of high-detail technical database. ${ }^{15}$ Three-dimensional data acquired on urban centers, coming from both image-based and range-based systems (Figure 2,) could easily be integrated with other metric information coming from direct surveys and cartographic systems, in order to obtain a correct georeferencing and scaling of the produced models. Considering the different survey techniques and sensors for the generation of realistic 3D models, defined by a good metric quality and a detail coherent with documental aims, the researches of urban documentation carried out in recent years have highlighted as best approach for the digital survey the integration and combination of different acquisition tools

14. L. De Luca, La fotomodellazione architettonica (Palermo: Dario Flacovio Editore, 2011).

15. L. Paris, "Quantità e qualità nell'utilizzo dello scanner laser 3D per il rilievo dell'architettura," in X Congreso International Espresiòn gràfica aplicada a la edificaciòn (Alicante: APEGA, 2010). 
and modelling techniques, developing documentary systems, based on integrated methodological protocols, that combined the potential of different approaches to complementary investigative solutions.
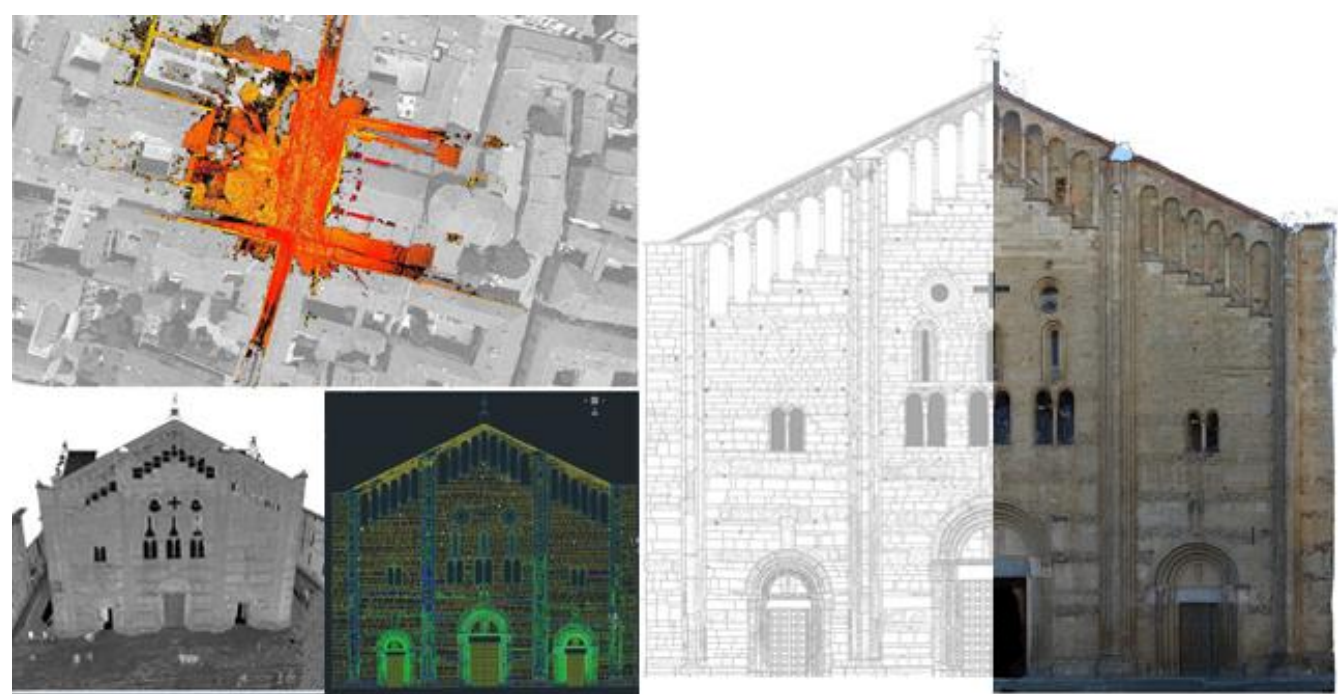

Figure 2. Image of Global Point Cloud Recorded by Scans from Laser Scanner Survey Campaign in a Portion of the Study Area of the Historic Center of Pavia. Starting from the Single Positions, the Merging Process Followed the Acquisition Path according to Closed Polygons of Shooting Stations, then Connected in the Obtained Blocks and Defined in the Urban Mesh. Below, the Façade of San Michele with the Front Re-drawing and the Materic Ortho-front.

The exclusive application of a single 3D surveying technology has not allowed, at the moment, to reach satisfactory results in different working conditions and in terms of geometric accuracy, portability, automation, photorealism and low costs, with the same efficiency and flexibility, without neglecting needs of representation and visualization. The objective of experimentation of methodological integrations of digital urban documentation has confirmed that of obtaining an accurate, metric and constructive description of the territory and its more or less complex built fabrics till individual buildings, constituting powerful operational protocols for the analysis of architecture to support reconstruction, restoration and planning. The acquisition and processing of data was conducted taking into consideration the specific characteristics of each methodology, both in terms of reliability, accuracy and format, and for the purpose of mutual integration, to include all products in a common database, aimed at different applications: cartographic documentation, analysis of urban fronts, structural analysis, mapping of critical degradation, cultural dissemination. The systematization of data has allowed the reading and understanding of each environment and urban area surveyed not only in its singularity, but also in function of its broader morphological context and in the deepening of relationships within the aggregates, expanding the possibilities of study and constructive understanding. The applied methodologies have led to the creation of dynamic three-dimensional databases on historical urban centers, implying the addition 
of a new information level and the consequent design of corresponding digital archive, able to take into account of 3D data both for the geometry and morphology of surveyed buildings (useful for protection and conservation), both in the virtual form of containers of information useful for the management of sites (information aimed at restoration and for scientific purposes) or for the use by the public through Virtual Reality. In this phase, urban metadata has acquired increasing importance, until their consideration as constituent part of the definition of a digital object, ${ }^{16}$ inseparably composed of informative content and a series of inputs that make the sequences of bit meaningful, identifiable, and accessible for their use, storage, conservation, dissemination and other management operations. It was possible to divide data, organized according to acquisition methodologies, into source data, such as photographs and point clouds, and processed files, corresponding to the certified databases, finally reaching output products, such as graphic drawings, critical maps, censuses and interactive 3D models, as most effective products to understand the spatiality of more complex environments and built centers. The purposes of these models has been multiple, from the development of documentation systems and census for complex architectures to simulations in virtual environments of historic centers, conducted to evaluate specific structural conditions, related to the diagnostics of materials and the state of degradation, to their use in the project and for planning activities corresponding to both architectural and urban scale. ${ }^{17}$ The experimentation also involved modelling systems that exploited the opportunities offered by virtual reality or augmented reality, where three-dimensional models can be interacted in virtual space by users, configured as avatars, moving in first person and observing the new virtual representation on a tablet or smartphone device through privileged informatics platforms for the open and widespread use of the digital image and its interpretive systems.

\section{Cases of Research in Central Italy, from the Documentation to the 3D Model $^{18}$}

Montepulciano, Development of a Cognitive Framework of Historical Center

Starting from experiences conducted from the joint laboratory LS3D Landscape Survey \& Design, of University of Florence and University of Pavia, between 2003 and 2015 some surveys were carried out in the planning and redrawing of urban centers in Central Italy. Through a specific agreement between the Department of Architectural Design of University of Florence and the Municipal Administration of Montepulciano, in the province of Siena, the realization of a cognitive updated framework of its historical center was

16. Like something (eg. an image, audio recording, textual document) that has been digitally coded and integrated with metadata that supports its identification, use and storage.

17. S. Bertocci and S. Parrinello, From the survey to the project Heritage \& Historical Town Centres. Information on urban regeneration (Firenze: Edifir, 2007).

18. The author of this paragraph is Francesca Picchio. 
developed. ${ }^{19}$ The aspects of the project have been defined by the need to describe the relationships between individual characteristics of single building units and surrounding urban fabrics by identifying the activities carried out within the urban context. The first project, started in 2003, aimed to check the quality of new residential systems, built or under construction, both from a morphological and typological point of view, establishing coherent development programs for the city's original historical nucleus. Within the second survey campaign, started in 2007, a new digital map in 1:500 scale return was created, as support of thematic readings $^{20}$ and new urban planning provisions. The survey thus led to the identification of thematic issues, and therefore to the data to which the outputs had to be able to respond. The cataloguing of various elaborates produced over the years allowed to establish a huge digital archive of images related to the description of each urban block of the historic center of Montepulciano. Thanks to this database, it was possible to identify, codify and then report to the general mapping system each front belonging to each building unit, every public and religious building, and for each one to represent its state of fact through drawing and photography. From survey to modeling, project phases have involved analysis, collection and selection of photographic data, 3D modeling and the drafting of required information. ${ }^{21}$ Following this process, the research project has set itself the dual objective of offering to visitors, physical and virtual, itineraries of fruition (fixed and mobile) capable of overlapping to real architectures a series of information in virtual mode. Such information is able to follow the visitor in the knowledge of the territory and the city, filling with the minimum environmental impact the gap between visual perception and knowledge. The project has provided to the visitor contextualised multimedia contents that can be accessed in any place and time in which fruition itself has significance, during the visit of the city but also in other moments and territories far from the city. Research has also allowed to create a procedural model that can be replicated in other areas and contexts, useful to make "known" the site and to give it a different light, even commercial where required, such as the creation of online stores, following the e-commerce idea that is bringing new life to little-known realities, allowing an amplified vision even beyond national borders.

\section{Development of "Territorial Museum" for the Conservation of Heritage of the} Sites along Via Flaminia

The aim of conservation and accessibility of urban sites outline problems not only concerning the management of survey, study and conservation campaign, but also, in the aim of creating a network of museums, problems related to the

19. S. Bertocci and S. Parrinello, "Rilievo e Piano di Gestione per il Centro storico di Montepulciano," in Conference proceedings EARCOM 07 Sistemi Informativi per l'Architettura (ed.) P. Clini, N. Lancioni and R. Quattrini (Firenze: Alinea Editore, 2007): 108-113.

20. The thematic charts represent a system of description and representation of the historical settlement system and of cultural assets and contribute in a fundamental way to the interpretation of the heritage itself, highlighting its specific characteristics and peculiarities.

21. S. Bertocci, S. Parrinello, S. Bua and F. Picchio, "Montepulciano 3D: modelli virtuali per l'urbanistica e lo sviluppo dell'ambiente urbano," Town files-città stratificate V (2014): 1-20. 
improvement of correct use and planning of these sites, through the realization of an executive program of intervents in order to ensure the best preservation of heritage itself. Within the territory of Umbria, crossed by the ancient Roman road of via Flaminia, a framework of digital documentation was developed ${ }^{22}$ in order to ensure the dissemination of data inside a Virtual Museum ${ }^{23}$ for every type of belonging settlements. Conservation and accessibility to heritage sites as the city of Carsulae, in Sangemini, the settlement of Massa Martana and the different rural churches and monasteries present in the territory, have been the basis for a research of urban documentation between 2005 and 2010.
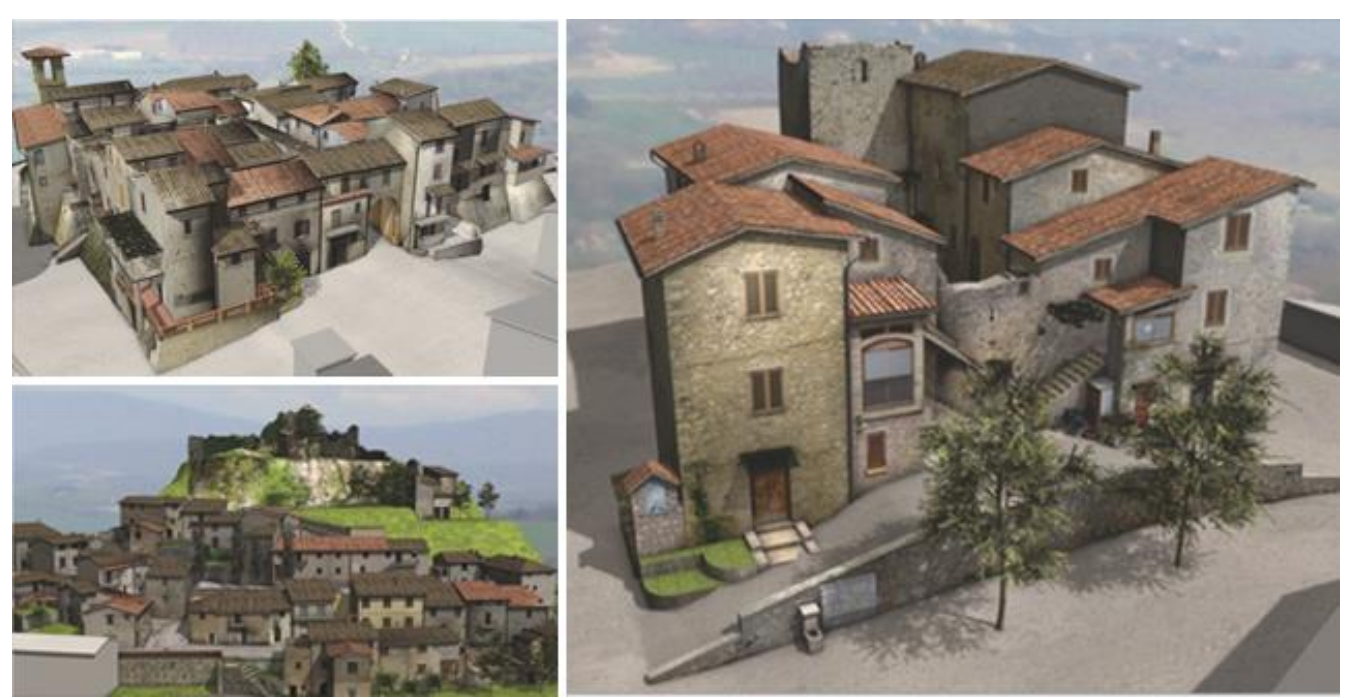

Figure 3. Digital Documentation using 3D Models for Historical Town Settlement along via Flaminia near Martani Mountains

The "territorial museum," as a social-cultural space, is able to articulate common conceptual data. The purpose of a territorial museum, as well as a didactic museum, has been to highlight and facilitate the construction of logic connections within the cultural heritage. To this aim, surveys of the sites along Via Flaminia, near Martani Mountains, have produced a useful documentary database at the territorial scale. For each site of documentation, surveys were conducted through the use of multiple methods of integrated measurements. In Carsulae archaeologic area, laser scanner survey allowed to develop a data archive of 3D experimental models (Figure 3) to able to permit the navigation in the database both remotely and within the site. A preventive conscience emerged towards the heritage of the area and its safeguard; this consciousness, in particular, has used social organizations and institutions to protect a specific set of heritage and environments exposed to devaluation or de-significance. Therefore, structures and relationships systems have been projected with the aim to develop a

22. S. Bertocci and S. Parrinello, "The Flaminian Way in Umbria: an integrated survey project for the study and conservation of the historical, architectural and archaeological features," in From Space to Place (Oxford: Hadrian books, 2006), 427-432. 2007).

23. F. Antinucci. Musei virtuali. Come non fare innovazione tecnologica (Bari: Laterza, 
transformation from site into a museum. The object to be safeguarded was moved to another dimension, spatial but virtual, where some of its aspects have been captured and transformed to allow its availability and "web navigation."

\section{Research Activities in the Territory of the City of Pavia and Oltrepò Pavese Pa $^{24}$}

Through the studies and the previous acquired experiences, in part described in the previous studies, in recent years LS3D joint laboratory and DAda Lab of University of Pavia have analyzed, digitally acquired and elaborated documentation systems of the cities of Pavia and Barbianello in Oltrepò Pavese, trying to find a solution to the widespread problem in the national territory of the inability to put different models of analysis into a unique system, launching researches on the documentation of their respective historical centers. The city of Pavia, the historic Lombard capital in the context of Northern Italy, has a rich architectural collection of traditional constructive and typological systems due to the numerous cultural currents and historical events that have affected it over time. The buildings of its historical center have a series of morphological features, common to the Italian historical villages, linked to the original Roman plant, affected in its current form by urban renewal interventions of the last two centuries that have led to profound changes in the city's image, including the demolition of the perimetric wall system. The consequent development of the external infrastructural road-ring has defined a new perimeter of the urban nucleus, changing the existing relationships between historic nucleus and expansion areas and developing permeable systems of relationship between the city, the hinterland of communal fractions and monumental centers and the landscape system that extends till the mountains of Oltrepò Pavese. The relationship between the historic center of Pavia and the small cities beyond the river Po valley, such as the center of Barbianello and its municipal fractional systems, have proved to be multiple, both historically and from bibliographic research on political events and initiatives promoted by noble families active in the area, and with regard to reciprocal internal influences perceived by the surrounding regions on architectural systems, in the use of materials and constructive techniques characterizing the Lombard tradition. ${ }^{25}$ The use of the brick or "backed clay" used both as a structural element and within high-quality decorative systems of local craftsmanship, coupled with the typological characterization of wooden coverings, internal wall coatings and the systems of parks and gardens in the urban area, allowed to find comparative research systems. These fields of analysis guided the investigation for the verification of systematic protocols, and at the same time, within the diversity of the analyzed contexts, they have determined precise approach variations in the investigation phases in order to obtain a set of elaborates useful for the different studies. To understand the development of the case studies presented below, a methodological protocol has been adopted articulated on different

24. The author of this paragraph is Raffaella De Marco.

25. F. Del Vecchio, La Lombardia paese per paese (Firenze: Bonechi, 1991). 
processes in relation to the urban documental purposes. ${ }^{26}$ A historical survey of territorial systems has been conducted a priori, allowing a careful and precise identification of the historical political context in which these systems have developed. The evolution of urban built systems has been studied through the analysis of masonry stratification and bibliographic knowledge, to facilitate the understanding of the urban spaces examined; finally, the subdivision of the relative historical centers into areas, sub-areas, aggregates according to the dimensions of the context to be analyzed was undertaken. In these spaces the formulation of cataloging systems was started, through which metadata on building units were collected, containing conservation and analysis status relating to the conditions of the individual buildings and fronts, in their structural and architectural typologies. The main idea of the projects was the possibility to investigate all the constitutive characteristics of the urban image and the set of relationships existing between the single building and the surrounding urban context. Finally, the integrated survey determined a questionable and implementable 3D model useful for conservation, documentation and planning purposes. In response to the problems encountered, common to the historic centers and Italian villages, the research lines were tested on the following two case studies, for verification of instrumental and methodological operability aimed at the development of models and digital databases of urban systems addressed both to the individual citizen and to the municipal administrations for objectives of census, safeguard and musealization of historical centers.

\section{Pavia, a Database as Protection of the Historic Center from Natural Disasters ${ }^{27}$}

The city of Pavia distinguishes itself as a valuable cultural and architectural heritage of Romanesque imprint placed in a context closely related to events and calamities of natural hazards: the presence of Ticino river is an historical cause of flooding phenomena (among them, the recent in 1994) that have cyclically involved the margins of the historic center, the perimeter of old bastions and churches, and the area beyond the shore of Borgo Vecchio. In addition, the recent rise of seismic phenomena in the national territory has also affected Po valley, in past formerly considered as a "non-seismic" area, from events of increasing magnitude, with a significant impact on the historical heritage. In the last few decades, some research initiatives have been interested in structural analysis and interventions for the safety of some monumental complexes of the historic center of Pavia, such as for Dome cathedral and the historical medieval towers, confirming a critical static situation of buildings supposedly extended to the entire urban context. In parallel to the fragile structural condition of complexes of the historical center, there is an increasing crowding of the urban area linked to its university nature, where the continuous increase of population, of international and intercultural provenience, presses towards new management systems and the creation of public and infrastructural services

26. S. Parrinello and F. Picchio, Barbianello e Palazzo Nocca: un progetto di documentazione per lo studio dell'Oltrepò pavese (Firenze: Edifir, 2017).

27. The author of this paragraph is Raffaella De Marco. 
that can be developed through virtual prototypes of smart city, where the digitized image is entrusted with the task of orienting and coordinating relationships between user and landscape, decomposing and re-assembling it into themes for analysis queries. The documentation started on the case study of the old town of Pavia is centered on the reading of morphological complexities of the space and their graphic transposition by drawing. This survey tool had, as main goal, to explicit the spatial components of the city and to subdivide the area into subsets in order to facilitate the acquisition and management of data. The subdivision was organized on levels, based on signs and structures present in real space: open spaces, urban paths and volumes were configured as macro categories that relate to points that determine elements of singularity in the image of fronts and urban structure. In this scenario, towers, domes, architectural elements and other discernable become autonomous and privileged entities in the reading of space, dominating the general urban image of street fronts. The drawing, as more complex as the number of categories to describe, required combined actions of perceptual capacities, to identify it, and representational solutions to express it. Synthesizing the data obtained from drawing and decomposing the space to set up survey campaign for macro-areas was a necessary task for space knowledge, condensing into a single cultural mediation system a communicative system that could be easily understood. ${ }^{28}$ The integrated survey campaign launched in 2013 in the historical center of Pavia, for the documentation of a sample of urban blocks including Garibaldi's original Roman decumano and the Basilica of San Michele Maggiore, has determined a set of questionable, navigable, integrable and selectable data for exporting images describing 3D space and environments. The area was selected within a perimeter of particularly complex urban fabrics, capable of representing many of the major identifying features of the historic center of Pavia. For this purpose, laser scanner survey has allowed to obtain useful information about hazard's effects by comparing the surveys of different point clouds (Figure 4) carried out over time, defining displacements in millimetric terms, abnormalities and levels of structural risk and producing a monitoring tool capable of be updated over time and to be constantly consulted at multiple layers of depth. The developed database thus provided an already pre-established information system, where the querying by set of search values allows users to interface directly with data; in this way it is possible for experts to develop targeted surveys according to displacement tolerance ranges by evaluating their value scales in each particular situation ${ }^{29}$ (Figure 5.) In this sense, photogrammetry has shown as the most versatile technique for the determination of superfetations due to the degradation of buildings and more in detail of wall surfaces. Within the study phases, some criticalities were found with both range-based and imagebased acquisition methodologies due to the morphological complexity of the context, such as the progressive increase in the vertical dimension of palaces,

28. C. De Vecchi, La rappresentazione del paesaggio. Funzione documentaria e riproducibilità tecnica (Milano: CUEM, 2000).

29. S. Parrinello, F. Picchio and R. De Marco, "New generations of Digital Databases for the development of Architectural Urban Risk Management," in Proceedings of Le Vie dei Mercanti XV International Forum World Heritage and Disaster (Napoli: La scuola di Pitagora, 2017). 
compromising in part the reading of architectural elements, because of "shadow areas" of survey. In some cases, it was possible to implement data by increasing the number of acquisition positions; however, it is desirable to apply integration campaigns with aerial scans and drone surveys to determine data in the higher parts of buildings, compared to street urban section.

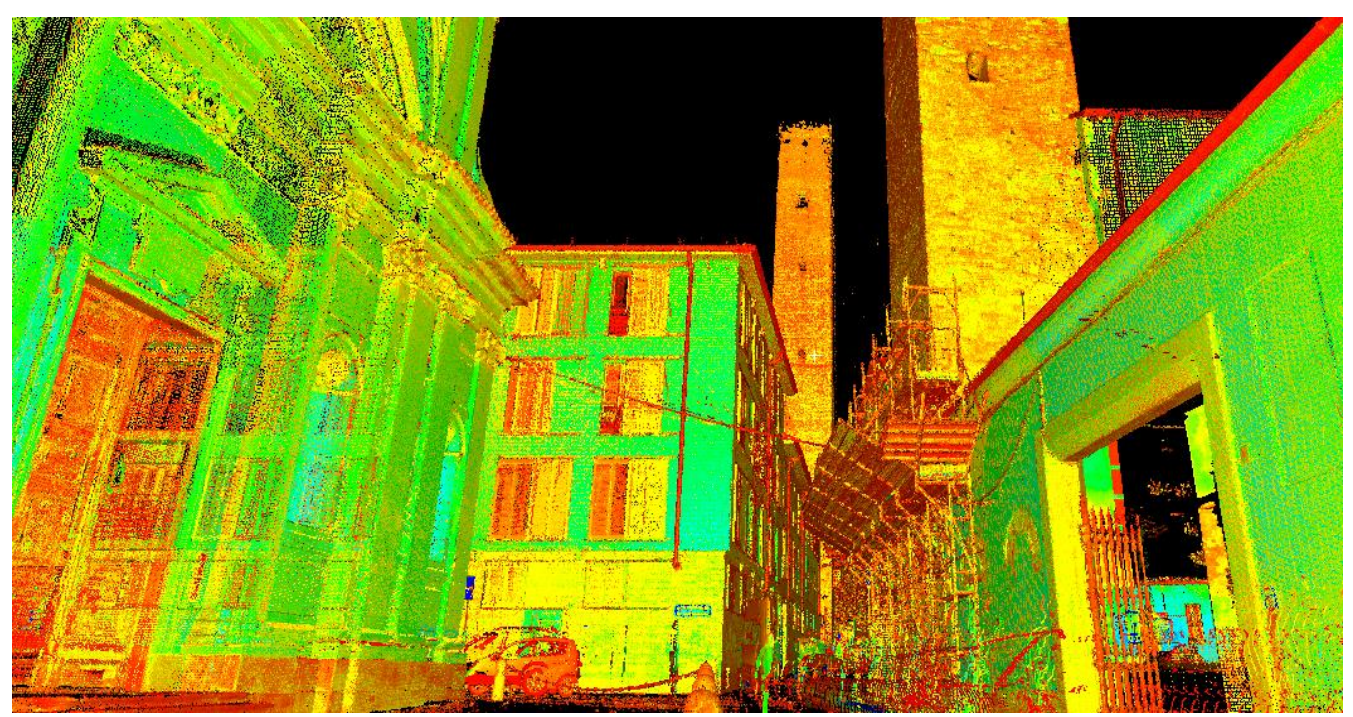

Figure 4. Point Cloud View, along Via Luigi Porta in Pavia. It is Possible to Distinguish Building Units and the Monumental Complexes of Medieval Towers (San Dalmazio Tower and Belcredi Tower.) The Point Cloud Confirms itself as a Highly Reliable Tool for Measuring Urban Architectural Morphological Characters.
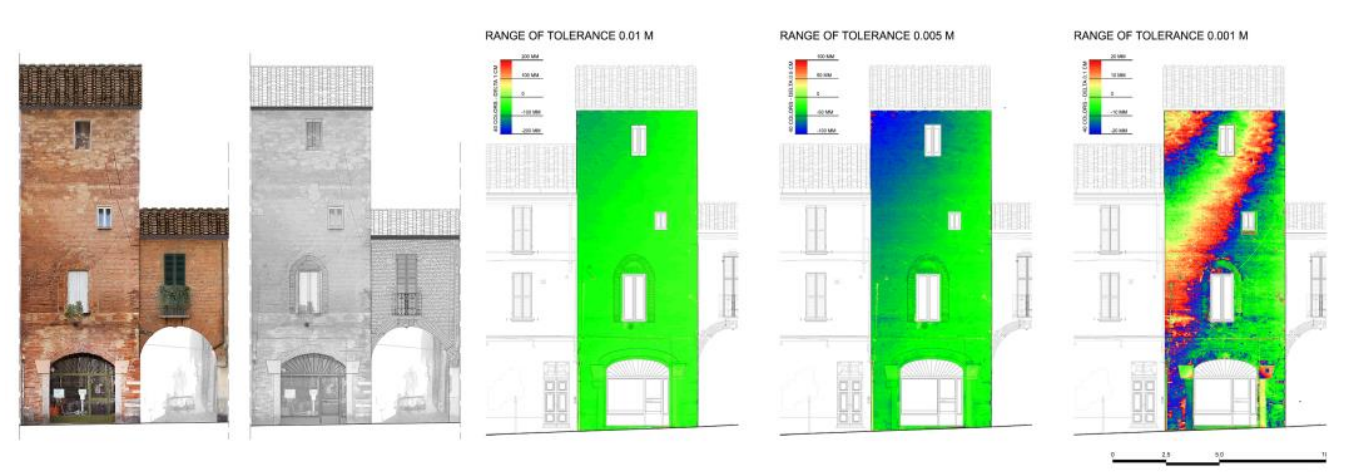

Figure 5. Two-dimensional Drawing, from Point Cloud and Photogrammetric Survey, of the Street front of a Medieval Tower Adapted to a Residential Unit, in the Historic Center of Pavia. Analysis of Structural Deformations on Different Tolerance Ranges (0.01 - 0.005 - 0.001 Meters.)

The integrated approach of acquisition of metric and colorimetric urban morphology allowed a complete assessment of most visible aspects of conservative state of building units, material degradation pathologies and structural evaluations on deformational and kinematic phenomena such as calamities represented from earthquakes and floods to which the area is subject. 
The potential of the acquired digital model resides in its interactivity, in its threedimensional view not limited to representative goals but developed between content and cognitive interface, between documentary source and archiving tool. ${ }^{30}$ The scientific value of the 3D database was underlined thanks to its measurement accuracy for architectural and diagnostic analysis, diversifying data according to possible queries variables. A subsequent phase of reprocessing of the acquired data has started with the elaboration of useful census records linked to a G.I.S. system questionable, implementable and interactive, through the definition of homogeneous descriptors, specific fields of informative contents that order and structure the urban chaotic reality according to architectural, technological and cultural sectors of elements and services. The heterogeneity of urban objects, visible both as architectural buildings and technologic and commercial containers, has been reflected in the vastness of compilable fields aimed at structuring a synthetic cognitive investigation and immediate understanding from the various disciplinary sectors involved. Documentary research on the historical center of Pavia resulted in an interactive archive system, still under implementation, able to provide information on operational actions on the city planning, covering the areas of investigation and intervention from structural monitoring to service portal. The cloud model combines both 3D graphics interface and the structuring of an expandable database not only in architectural and engineering disciplines but also in terms of broader and heterogeneous content, from landscape management practices to safeguard environmental protocols, urban census and increased use of services by users and citizens. Through the study and a continuous research, it is therefore possible to obtain useful information for the purpose of a better management of the territory aimed at the prevention of seismic calamities and alluvial problems.

Barbianello, a Database as a Requirement for Urban Planning and Development ${ }^{31}$

The case study ${ }^{32}$ of the historic center of Barbianello, in the rural countryside of Oltrepò Pavese, was organized with the main purpose of analysis and understanding of landscape by identifying the relationships between buildings and environment. The study of the structure of the site, in its natural and artificial systems, led to the elaboration of a vast knowledge framework, appropriate to the synthesis and interpretation of the city, with the aim of preserving and enhancing the architectural, cultural and historical reality to solve the issue of urban planning and building control that concerns this community as the many surrounding

30. S. Parrinello, F. Picchio and R. De Marco, "Pavia 3D: Reading and decomposition of the city for the construction of dynamic databases on heritage," Vestnik permskogo nacional'nogo issledovatel'skogo politehničeskogo universiteta. prikladnaâ èkologiâ, urbanistika 1 (2017): 33-45. ISSN: 2409-5125.

31. The author of this paragraph is Pietro Becherini.

32. In collaboration with the Municipality, the documentation of Barbianello and Palazzo Nocca was carried during 2015-2016, with the organization of thematic seminars by Prof. S. Parrinello, Department of Civil Engineering and Architecture of University of Pavia, and Prof. S .Bertocci, Department of Architecture of University of Florence, with activities of students, researchers and graduate students. 
centers. The objective was therefore to allow the analysis of the image, the state of conservation and the census of urban fronts in order to create an urban planning tool aimed to maintain homogeneity between neighboring municipalities, preserving the cultural historical value of the territory. These rural realities are lower involved in tourism, but they have been characterized by valuable cultural currents in history of Lombardy and have a great potential in the direction of historical tourism. A research activity was started, which, through the integrated survey, has foreseen the structuring of a laser scanner and photogrammetric analysis campaign of the territory. This was developed in two phases: in the first one, more general, the municipality territory and the hinterland were analyzed at territorial level and then redrawn; in the second phase, the analysis was deepened and focused to the case of the historic center of Barbianello where the main street fronts were acquired, as well as the census of building units of the center, in order to have a detailed catalog of the reality of the place. This type of research represents one main tool for any kind of intervention or prevision, considering future planning, management and preservation of the historic center. Following this iter, the "Territory Use Card" was written, serving to represent the state of utilization of the territory deriving from the physical and morphological characteristics of the municipality. After a preliminary phase involving an indirect analysis (represented by historical and thematic mapping of territorial development, by the consultation of the Territorial Government Plan and given by satellite images at different scale of territorial survey) and a direct analysis (given by a photographic campaign assisted by the creation of eidotypes of significant morphological points by means of which it was possible to describe and analyze the territory,) an identification of the objective territorial components, defining the site structure as a result of the coexistence of the natural and artificial system, was carried out. The first one defines the structure and properties of components of a specific territory and its environmental system: configuration, hydrographic position and vegetation. The second system is defined by the part of artificial environment and it concerns the drawing and complement of urban context: this is composed by infrastructures, settlement structure and open and equipped spaces. Cities, based on a "inertia" phenomena, tend to grow along paths and directional axes that keep their position unchanged over time. Different housing densities have been identified within the territory, dividing it into urban centers, groups of houses and isolated ones. Perceptual analysis was later started as an interpretation of reality by a typical user. This type of research is part of the study of analytical interpretative methodologies of reality in close contact with cultural components that can offer reading key of qualitative aspects. Starting from the surveyed information, distinctive signs that allow a division into homogeneous zones have been identified in the territory to describe the peculiar characteristics of analyzed landscapes. ${ }^{33}$ The elements considered were Environmental Layers, Surfaces, Margin Lines, and Centers.

33. A. Dell'Amico, "Survey and documentation for the valorization of the landscape and historical center of Barbianello," in Proceedings of X Encuentro Internacional CIM "Ciudad Imagen y Memoria” (Santiago de Cuba: Ediciones UO, 2017). 

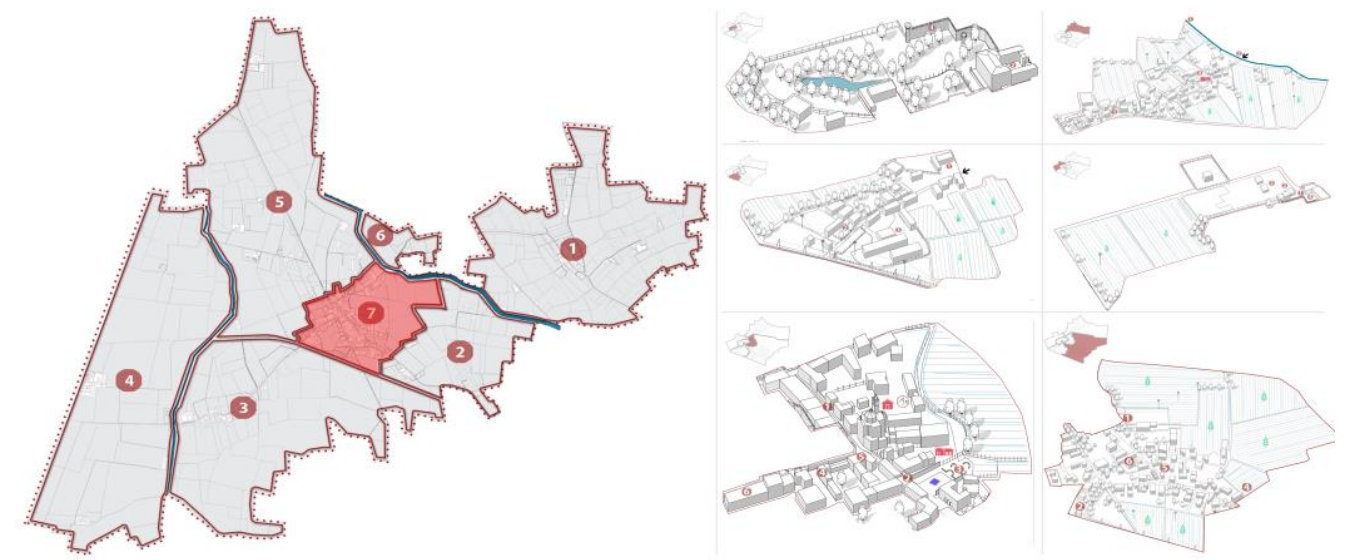

Figure 6. The Diagram Below Shows, on the Left, the Subdivision into Macro Areas of the Territory of Barbianello; in the Right, the Subdivision of the Macroarea 7, Previously Highlighted in Red, in the Relative Micro-zones, Including the One Analyzed through an Integrated Survey of the Historic Center of Barbianello.

Barbianello's communal territory has presented an almost homogeneous morphology with few small inhabited centers; within its territory, different visual or perceptual limits such as channels, trees, ditches and infrastructures has allowed to distinguish homogeneous areas within the municipality, in particular 7 macrozones have been identified (Bottarolo, casa Storini, San Re area, Cascina Gilberta, Frappeta, Cemetery of the Assumption and Barbianello's center). A "macro-zone" (Figure 6) is therefore a homogeneous area located within the municipal territory based on the limits established during the analysis phases. The subdivision of the landscape into Macro-zones has allowed to create a territorial hierarchy in support of landscape analysis and categorization, in order to create a significant representation of reality through codes and according to representative signs, useful for modeling the space structure. Within each macro-area, margins were analyzed and centers, nucleus and blocks were identified. Then also paths were analyzed, defining for each one the type of mantle and its state of conservation, the presence or absence of highlights and the amount of traffic present in certain time slots. Macro-zones have been divided into micro-zones, representing homogeneous regions determined by a logic of hierarchization to order the spaces, and, similarly to macro-zones, they were defined by physical and perceptual limits. The detection of micro-zones served to deepen the analysis carried out from a wider, territorial scale to a more detailed point of view and going to study the individual elements that characterize physical and relational space. Each area has been analyzed for the destination of use and the distinctive features of its elements, identifying its margins and analyzing agricultural and built areas. In the case of agricultural areas, the type of cultivation was identified and the change of landscape during the periods of the year was analyzed; as for the built areas, the different types of buildings have been identified. In the case of Barbianello municipality, macro-zones have been distinct in homogeneous areas, some composed of compact urban fabrics of modest size, others mostly agricultural areas with groups of houses or scattered farmhouses. Through thematic maps characterized by different levels of analysis, the various considerations on the 
municipal territory were summarized. Following the detailed urban system analysis, it was possible to express considerations of future planning, management and conservation activities in the center. By careful analysis of each macroarea, through seasonal comparisons made both in the same year and in different years, it was shown that, as time passed, specialized crops have been developed, which have transformed the agricultural landscape. ${ }^{34}$ This great development led to the need to upgrade production and distribution facilities. Following the analysis of the territory, a laser scanner survey in the historic center of Barbianello was carried out, since it was considered the most useful in creating an urban spatial planning tool. This phase was carried out by programming the position of the instrument along the main streets of the historic center and in some of secondary streets, located on the border between cultivated area and the city center, developing the mapping of facades. This census analysis has led to the drafting of thematic cards (Figure 7) which enabled a general overview of fronts information.

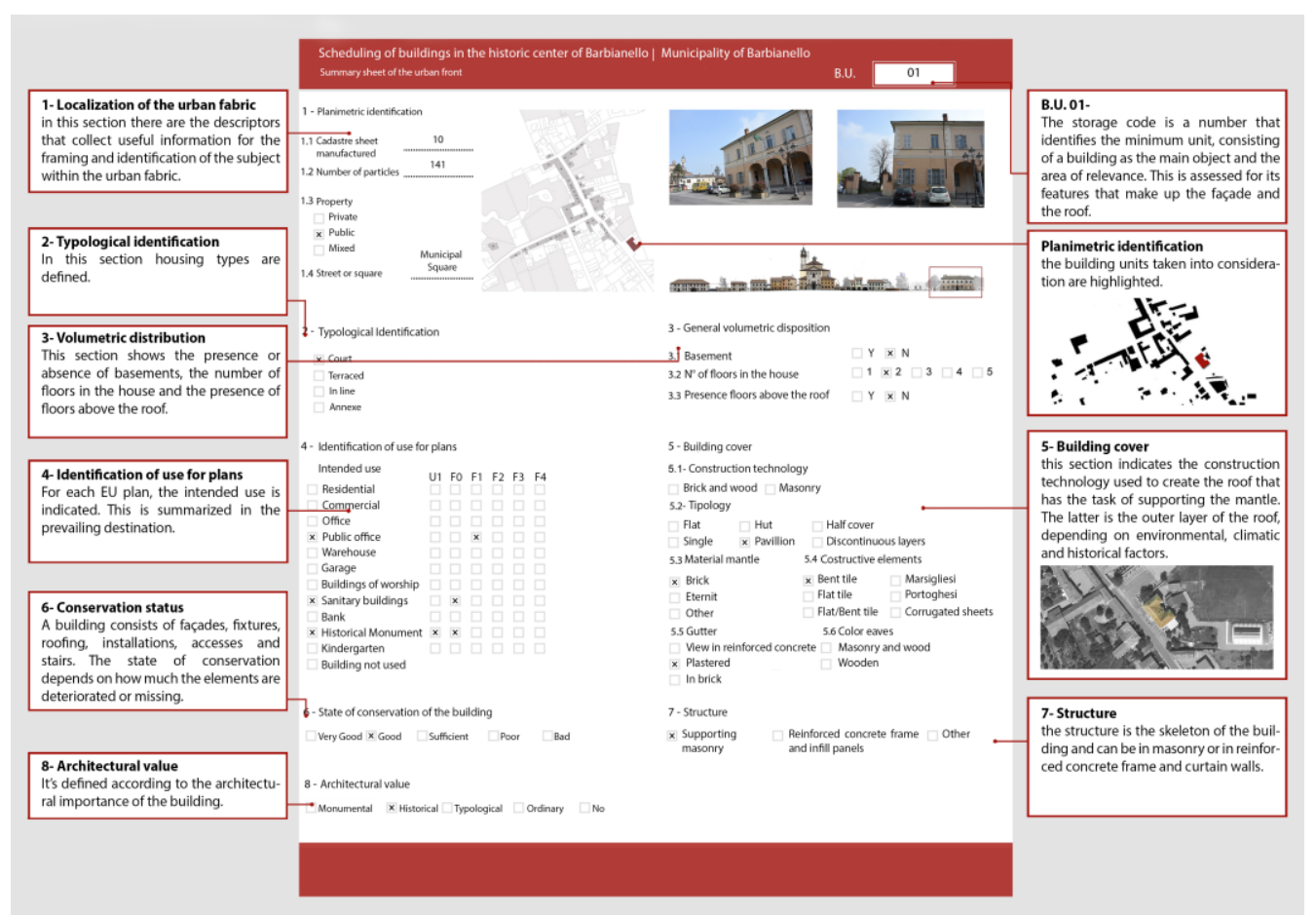

Figure 7. Census Scheduling was used to Reorganize Surveyed Data, to Organize Levels of Reading Defining the Significant Image of Urban Context. A First Analysis was carried out Directly on Site where Each Front was analyzed to Define the Structure of the Card. Subsequently Fronts of the Historic Center were divided into Building Units. Each Board has been referred to the Main Front of Each Building Unit, Identified in a Well-defined Volume by Type, Building Use, Height, Number of Floors, Architectural Characters.

The thematic drawings were important since they helped to draw a cognitive

34. F. Picchio and A. Dell'Amico, "Sings and structures of Oltrepò Pavese: summary for the graphic representation of the traditional cityscape," in Proceedings of $5^{\circ}$ INTBAU international Annual Event (ed.) G. Amoruso (Milano: Springer, 2017). 
framework based on the conservation and management of the territory, they described and represented the historical settlement system, they allowed to understand the heritage of the center, highlighting its specific characteristics and peculiarities, and finally they constituted an effective tool for immediate reading of the urban aggregate. The main axis existing between Palazzo Nocca and Church of San Giorgio has determined an integrated survey that has provided for the study and analysis of Palazzo Nocca, the most important historic building in the city, obtaining a set of digital documentation to enhance the building and thus giving value to the whole context of Barbianello, including the adjacent centers. To implement the research, considerable interest has involved the study of the Palace and its relevance within the territory. The acquisition was carried out on internal environments today used by the Municipality, on the exterior facades overlooking the park and the urban courtyard and the cellars below the building, with access from the street. The obtained point cloud in this case had a purpose that was set in the future perspective to give more breath and emphasize a not well enhanced reality. 3D virtual modeling of environments acquired through Structure from Motion photogrammetric methodology was used for materic restitution of architectural surfaces and for defining a surface mapping. The collection of metadata for each single facade and building highlighted its characteristics, thus enabling them to be recorded in an increasable digital database and to be able to rely on future comparisons of the preserved state of analyzed fronts (Figure 8.) 3D models, integrated and scaled with metric data acquired by the measurements, represented for the first time a category of documentary material, important to define through a digital way Palazzo Nocca. ${ }^{35}$

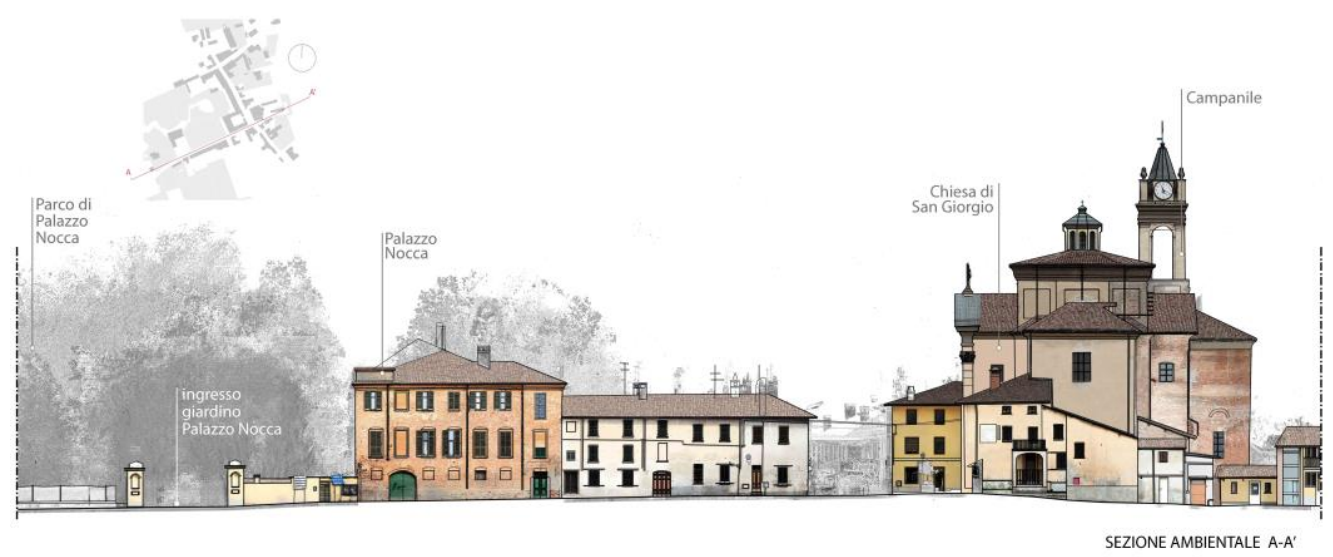

Figure 8. Environmental Section that Cuts the Village of Barbianello from East to West. In Particular, we can see the Important Relationship that Emerges between Palazzo Nocca and the Church of San Giorgio.

The acquisition of this data made possible to draw a digital archive from which to gain to define studies on the territorial context. In this particular case,

35. Localized in the center of the town of Barbianello, the 18th-century mansion was the residence of Beccaria family, then from 1820 of Nocca family that some decades later, with the chemist Carlo Francesco Nocca, confers the garden with a symbolic value of alchemical matrix. 
the goal of drawing a Color Plan, ${ }^{36}$ for the conservation and redevelopment of urban spaces, has represented a fundamental cognitive step for conscious planning, preserving the unitary image of urban fronts. The Color Plan has constituted therefore a fundamental tool for coordinating the maintenance, renovation and refurbishment of wall parameters that include not only the colorimetry of the facade, but also the set of architectural components that contribute to define the color perception of the street axis. The original colors of facades have been found into iconographic and photographic documents and on the traces of weak and contradictory colors survived. Colors of visible facades have been detected and reproduced as faithfully as possible, thus representing the palette of colors in the historic center, and then the paintings were identified. The census listing of buildings in the historic center of Barbianello constituted the basis for subsequent planning interventions. This allowed a synthesis of the current urban state, with the identification of critical and dissonant elements with the character of the urban context. Within the planning guidelines identified, it was highlighted how the historic center does not need significant interventions on urban fronts, as is evident for example from the analysis of a portion of the front of Via Barbiano, while it was considered more urgent a selective procedure for the demolition of the entrance to Palazzo Nocca due to the profound deterioration conditions. For the other building units, minor interventions were shown for the recovery and replacement of architectural elements, restoration of masonry surfaces, tamponing of windows, removal of plates, signs and road signs that conceal or disturb the decorative devices, until the replacement of wall cladding materials with the most suitable types and in harmony with the territory.

\section{Conclusions $^{37}$}

"In the last fifty years our country has experienced the most radical and most extraordinary socio-economic and cultural transformation of its modern history. The migrations from the South to the North, from the countryside to the city, from the mountains to the plains, from the inside to the coasts, have disrupted and upset the territory. Rural areas are scattered while the peripheral parochial structure that had resisted fearless for centuries dissolved like snow in the sun. The ancient villages were studied while the building speculation destroys the landscape, the most important and most envied cultural asset of historical Italy. The ancient villages were studied while the building speculation destroys the landscape, the most important and most envied cultural asset of historical Italy. The entry into Modernity, in other European countries which had been consummated a hundred years

36. The Color Plan is a tool for researching the quality of public space by identifying the actions to be taken to conserve and enhance urban and environmental architectural components, which together define the fabric of historical nucleus and that contribute to the identification of a place.

37. The author of this paragraph is Sandro Parrinello. 
earlier, has tumultuously exploded here in the second half of the twentieth century." (Valentino Baldacci) ${ }^{38}$

The potential of an archive and its digital model lie in the mechanisms of interaction between data and image and in the systems of use between user and database. In this sense, the 3D model facilitates the movement and the connection between information content and virtual space, enhancing a cognitive interface moving every reflection towards virtual reality. The cloud model combines both 3D graphic interface and the creation of a heterogeneous expandable database, including document sources, databases and archives and, in wider terms, every possible approximation of a qualitative data of the space or of a real function. The interactivity of the database through the obtained model aims to provide a navigable documentation system, decomposing the observed reality from the urban scale towards the architectural detail. The system interface should be able to provide different way of access to guarantee for the different kind of public a more appropriate way of use. Whereas, on one hand there are professional users and experts engaged in architectural recovery and planning, on the other hand there are private companies that can create data on network systems or more specific dealers who can enrich the information model about the specific business to activate virtual portals from which to promote their activity. Future city services are interconnected in databases of the present time and the image of the city builds itself into tablet and terminals of technical offices, becoming the mirror of a city providing multiple images of itself to contemplate and give answer to the "social identity." A city that offers more images of itself, whose dialogue moves on several media channels, will provide its inhabitants with a greater context in which to identify their own identity. For this reason, it is important today to continue to develop studies and research in this area. One of the main problems that remains today is that the results obtained require constant expenses for a continuous verification of the elements analyzed. As repeatable on the national and international territory, such a quantity of data is in fact useless if there are no continuous updates with the latest technologies and checks for those monuments that, otherwise, are destined to disappear, "eaten" by mother nature or by the non-care of man who, for restructuring, prefers demolitions for new buildings.

\section{Bibliography}

Antinucci, F. Musei virtuali. Come non fare innovazione tecnologica [Virtual museums. How not to make technological innovation.] Bari: Laterza, 2007.

Assunto, R. "Metaspazialità del Paesaggio" [Metaspatiality of Landscape.] In Il paesaggio e l'estetica. Edited by Rosario Assunto. Palermo: Edizioni Novecento, 1994.

Baldacci, V. Il Sistema dei Beni Culturali in Italia. Valorizzazione, progettazione e comunicazione culturale [System of Cultural Heritage in Italy. Valorization,

38. V. Baldacci, Il Sistema dei Beni Culturali in Italia. Valorizzazione, progettazione e comunicazione culturale (Firenze: Giunti Editore, 2004). 
planning and cultural communication.] Firenze: Giunti Editore, 2004.

Bertocci, S. and M. Bini. Manuale di rilevamento architettonico ed urbano [Architectural and urban survey manual.] Novara: CittàStudi, 2012.

Bertocci, S. and S. Parrinello. "The Flaminian Way in Umbria: an integrated survey project for the study and conservation of the historical, architectural and archaeological features." In From Space to Place. Oxford: Hadrian books, 2006, 427-432.

Bertocci, S. and S. Parrinello. "Rilievo e Piano di Gestione per il Centro storico di Montepulciano" [Survey and Management Plan for the Historic Center of Montepulciano.] In Conference proceedings EARCOM 07 Sistemi Informativi per l'Architettura. Edited by P. Clini, N. Lancioni and R. Quattrini. Firenze: Alinea Editore, 2007, 108-113.

Bertocci, S. and S. Parrinello. From the survey to the project Heritage \& Historical Town Centres. Information on urban regeneration. Firenze: Edifir, 2007.

Bertocci, S., S. Parrinello, S. Bua and F. Picchio. "Montepulciano 3D: modelli virtuali per l'urbanistica e lo sviluppo dell'ambiente urbano" [Montepulciano 3D: virtual models for urban planning and urban development.] Town files - città stratificate V (2014): 1-20. ISSN 1828-5961.

Brusaporci, S. Sistemi informativi integrati per la tutela, la conservazione e la valorizzazione del patrimonio architettonico e urbano [Integrated information systems for the protection, conservation and enhancement of architectural and urban heritage.] Roma: Gangemi, 2010.

Cianci, M. G. Dalla linea ideale alla città virtuale [From ideal line to virtual city.] Firenze: Alinea, 2008.

Clementi, A. Interpretazioni di paesaggio. Convenzione europea e innovazioni di metodo [Landscape interpretations. European convention and method innovations.] Roma: Meltemi, 2002.

Coppo, D. and C. Boldo. Rilievo urbano. Conoscenza e rappresentazione della città consolidata [Urban Survey. Knowledge and representation of the consolidated city.] Firenze: Alinea, 2010.

De Luca, L. La fotomodellazione architettonica [Architectural photomodelling.] Palermo: Dario Flacovio Editore, 2011.

De Vecchi, C. La rappresentazione del paesaggio. Funzione documentaria e riproducibilità tecnica [The representation of the landscape. Documentary function and technical reproducibility.] Milano: CUEM, 2000.

Del Vecchio, F. La Lombardia paese per paese [Lombardy country by country]. Firenze: Bonechi, 1991.

Dell'Amico, A. "Survey and documentation for the valorization of the landscape and historical center of Barbianello." In Proceedings of X Encuentro Internacional CIM "Ciudad Imagen y Memoria." Santiago de Cuba: Ediciones UO, 2017.

European Commission Directorate-General for Communication. The EU explained: Digital Agenda for Europe. Luxemburg: Publications Office of the European Union, 2014.

Marini, D., M. Bertolo and A. Rizzi. Comunicazione visiva digitale: fondamenti di Eidomatica [Digital visual communication: foundations of Eidomatica.] Milano: Addison Wesley, 2001.

Paris, L. "Quantità e qualità nell'utilizzo dello scanner laser $3 D$ per il rilievo dell'architettura" [Quantity and quality in using the 3D laser scanner for architectural survey.] In Proceedings of X Congreso International Espresiòn gràfica aplicada a la edificaciòn. Alicante: APEGA, 2010.

Parrinello, S. "Rilevare, disegnare e organizzare la città digitale" [Survey, draw and 
organize the digital city.] In Proceeding of UID Disegno e città. Edited by A. Marotta and G. Novello. Torino: Gangemi Editore, 2015.

Parrinello, S. and F. Picchio. Barbianello e Palazzo Nocca: un progetto di documentazione per lo studio dell'Oltrepò pavese [Barbianello and Palazzo Nocca: a documentation project for the study of Oltrepò Pavese.] Firenze: Edifir, 2017.

Parrinello, S., F. Picchio and R. De Marco. "New generations of Digital Databases for the development of Architectural Urban Risk Menagment." In Proceedings of Le Vie dei Mercanti XV International Forum World Heritage and Disaster. Napoli: La scuola di Pitagora, 2017.

Parrinello, S., F. Picchio and R. De Marco. "Pavia 3D: Reading and decomposition of the city for the construction of dynamic databases on heritage." Vestnik permskogo -, urbanistika 1 (2017): 33-45. ISSN: 2409-5125.

Picchio, F. and A. Dell'Amico. "Sings and structures of Oltrepò Pavese: summay for the graphic representation of the traditional cityscape." In Proceedings of $5^{\circ}$ INTBAU international Annual Event "Heritage, Place, Design: Putting Tradition into Practice”. Edited by G. Amoruso. Milano: Springer, 2017. 